\title{
Paving the way for the optimization of water consumption in the steelmaking processes: barriers, analysis and KPls definition
} \author{
and Elisa Piras ${ }^{7}$ \\ ${ }^{1}$ Scuola Superiore Sant'Anna, TeCIP Institute, ICT-COISP Center, Pisa, Italy \\ 2 RINA-Centro Sviluppo Materiali, Rome, Italy \\ ${ }^{3}$ Ferriere Nord S.p.A., Osoppo (UD), Italy \\ 4 Sofi Filtration, Espoo, Finland \\ ${ }^{5}$ Brochier Technologies, Villeurbane, France \\ ${ }^{6}$ IDENER, Computational Maths, Seville, Spain \\ 7 TenarisDalmine, Dalmine (BG), Italy
}

Teresa Annunziata Branca ${ }^{1}$, Ismael Matino ${ }^{1}$, Valentina Colla $^{1, *}$, Alice Petrucciani ${ }^{1}$, Amarjit Kuor Maria Singh ${ }^{1}$, Antonella Zaccara ${ }^{1}$, Teresa Beone ${ }^{2}$, Luca De $\mathrm{Cecco}^{3}$, Ville $\mathrm{Hakala}^{4}$, Davide Lorito ${ }^{5}$, Santiago Moreira ${ }^{6}$,

Received: 4 October 2020 / Accepted: 25 January 2021

\begin{abstract}
The efficient use of water resources is one of the main challenges of the steel sector, according to the European Union water policy. On this subject, monitoring and optimization systems, linked to the innovative water treatments, represent important tools to improve water management and the related energy use. The present paper describes a part of the work developed in the early stage of the project entitled "Water and related energy Hub Advanced Management system in steelworks - WHAM", which is co-funded by the Research Fund for Coal and Steel. The project aims at optimizing water consumption in the steelworks through a holistic combination of on-line monitoring and optimisation and innovative water treatment technologies. As different aspects affect water use in the steelmaking processes, in the first part of the paper, the main technical barriers and factors, that can impact on reuse and recirculation of wastewater and energy efficiency, are analysed. The main constraints on water management in the steel sector, such as fresh water availability, its quality and local legal requirements, were considered in order to maximise the water reuse and recycling. Furthermore, the main barriers, such as environmental issues and several costs, were investigated. In the second part of the paper, a set of Key Performance Indicators are listed. They aim at assessing and monitoring the water management sustainability in a holistic way, both in terms of environmental and economic performances, as well as of new water treatments efficiency and their economic viability. Key Performance Indicators will be used to monitor the efficiency of water management, aiming at achieving significant increase of performances. On the other hand, some of these indicators will be used as objective functions for problems optimization. The computation of the selected Key Performance Indicators will take into account both industrial data and results from simulations that will be carried out after the development of suitable tools in order to assess the feasibility of some relevant process modifications or the applications of new technologies.
\end{abstract}

Keywords: industrial water networks / water management / steel industry / Key Performance Indicators / optimization / analysis of barriers

\section{Introduction}

Among its priorities, the steel industry is committed to use water in a sustainable way in order to follow the Circular Economy principles and obtaining all related advantages from economic, environmental and social point of view. Water is used in steel production in different ways, depending on its availability, types of processes and plant

\footnotetext{
* e-mail: colla@sssup.it
}

operating conditions and local regulations. According to the Word Steel Association [1], the average water input for the integrated route and for the Electric Arc Furnace (EAF) route is 28.6 and $28.1 \mathrm{~m}^{3}$ per ton of steel produced, respectively, while the average water discharge is 25.3 and $26.5 \mathrm{~m}^{3}$, respectively. The overall water consumption per ton of steel produced ranges from 3.3 to $1.6 \mathrm{~m}^{3}$ and most of it is lost by evaporation both from direct product cooling and from cooling towers. Nevertheless, in steelworks water can be reused in a closed loop, although there are significant 
differences among various facilities with respect to the averages per ton of product. Usually, water reuse concerns cleaning and cooling water flows, aiming to its recirculation into the water process. The combination of different technologies makes wastewater reuse of up to $90 \%$ possible. During direct cooling water gets in contact with products. This produces the variation of temperature as well as of some water characteristics, such as suspended solids, oils, conductivity, hardness, that should be considered during the water treatments to reuse and recirculate it.

A valuable approach to calculate the volume of direct and indirect water consumption in production processes is the Water Footprint (WF). WF is a multi-dimensional indicator for water consumption. For instance, blue WF refers to the consumption of ground and surface water, green WF is the volume of rainwater consumption, and grey WF is the volume of polluted water from production of goods and services. The use of WF instead of conventional indicators was recently proposed for the steel sector [2]. A WP calculation model and a calculated WF of steel from a life cycle assessment perspective were developed. However, the assessment of WF in industrial sectors requires many data from each production step. Therefore, the availability of a simpler method to evaluate blue and grey WF is surely beneficial [3].

Regarding the energy consumption related to water circuits, pumping and some treatments need large amounts of energy. Specific electric energy consumption in water circuits can be affected by various factors, such as cooling system type, specific water consumption, efficiency of the pumps and cooling units, age of pipes, etc. Using water and related energy in a more appropriate way, through the closed circuit monitoring and the water leakages reduction, is a priority and there is room for improvement in optimization potential.

On this subject, developing and implementing an integrated water management strategy with water reuse and recycle [4], applying the Best Available Techniques [5] for the wastewater treatments, aim at reducing the environmental impacts.

Digital and smart tools contribute to water optimization. For instance, smart sensors can be used in the water and energy management processes. On the other hand, collected data can be treated and optimized through machine learning and artificial intelligence techniques [6]. In addition, online monitoring of water use can make it possible to control its specific consumption. The application of a digitalized water network system in a steel plant can make online monitoring, diagnosis and warning of water quality and quantity possible in all areas of the plant, by thus saving water through network optimization and control based on real-time data [7]. A recent study covered a superstructure-based modelling and optimization approach for industrial water networks, including relevant equations among different water utilities, flow rate and mass balance constraints and property constraints. This application in coal-based chemical complex can provide about $25 \%$ reduction in water flow rate, and, consequently, water system annual cost reduction of about $18 \%$ [8].

In general terms, the main factors affecting the industrial water performance are physical (flow velocity, temperature, pressure, etc.), chemical ( $\mathrm{pH}$, total dissolved solids, organic matter, metallic ions, etc.) and biological (aerobic and anaerobic bacteria). On this subjects, process waters from steelworks and their treatment optimization $[9,10]$ were studied as well as new water treatments to decrease or eliminate pollutants from different steelmaking processes resulted in improving internal water reuse [4].

Concerning water treatments processes, the application of Micro Filtration (MF), Ultra Filtration (UF) as well as Reverse Osmosis (RO) in different industrial sectors was assessed [11]. Some new membranes in ceramics, alumina, metals for MF and UF were applied [12,13]. However, they present significant limits when used in the industrial environment (e.g. in the steel sector). For this reason, the main challenge concerns the development of membranes avoiding blockage and easy to be cleaned. New monomers and new polymerization process as well as the modification of the structure of conventional membranes or the combination of different materials, the use of nanoparticles, were studied $[14,15]$. In addition, recent studies were focused on the assessment of the increase of membrane fouling, to choose the most effective cleaning method [16]. Membrane fouling is due to inorganic salts, microorganisms, colloidal material and other pollutants, which deposit on the membrane surface. Such deposits can reduce the membrane flux, the quality of treated water and, consequently, the treatment efficiency. Low membrane fouling can be solved through ad-hoc cleaning processes, but severe membrane fouling can lead to high degradation of membrane characteristics and, thus, to its replacement. For these reasons, the fouling characteristics are among the most critical factors for the selection of pre-treatment processes and chemical additives. The application of UF and $\mathrm{RO}$ to reduce salt concentration and the possible reuse of blowdown in some steelmaking processes were investigated. In addition, the assessment of process integration solutions through ad-hoc simulations before real implementation was carried out, considering technical constraints and saving resources and costs [17]. This has led, for instance, to the reduction of freshwater make-up by $20 \%$ through a modification of a part of the whole water network [18]. Moreover, the application of these techniques for producing demineralized water to be used in thermal power stations and in the regeneration of coke-making area wastewater in a steelworks were assessed [19]. Furthermore, the UF and RO can be applied for reducing salt concentration in brackish water or wastewater, to be reused in steelmaking processes. In particular, the water blowdown can be reused as make-up water in other processes with or without pre-treatments [20].

Although different solutions can be applied to optimize the water management and to reduce its consumption in the steelworks, different factors hamper these improvements. As general rule, within this paper we named these factors "barriers". Therefore, in order to evaluate the potential barriers, a wider variety of factors affecting water optimization in steelmaking processes need to be considered, which can be of technical, regulatory, infrastructural, environmental and economic nature. In particular, technical barriers require comprehensive and integrated strategies. Moreover, it is crucial to analyze the factors which 
most commonly lead to lack of efficiency within industrial water networks and water treatment processes as well as the factors influencing wastewater reuse, recirculation, energy efficiency and efficiency of monitoring systems.

In this context, Key Performance Indicators (KPIs) are tools that make the quantification of environmental, economic and social performances possible. In particular, the development of specific KPIs aims at applying this metric to simulation tools of steelmaking plants to investigate possible improvements in water management. The KPIs, used to aggregate data of a technology or a process, are quantified into a representative figure, that makes comparison to the reference case possible. In particular, KPIs can measure progress towards measurable objectives within business units of a process (e.g. benchmarking), in which the objectives/performance requirements have to be clear and the results need to be quantitatively/qualitatively measurable and comparable with the settled objectives [21]. KPIs present some specific characteristics, that, according to EUROFER [22] are, as follows: Representativeness, Comparability, Simplicity, Reliability, Quantifiable, Sensitive to changes, Cost Efficiency.

A single indicator usually refers to a specific environmental issue, while KPIs, grouped into a set of indicators (e.g. Indicator systems), refer to a set of environmental issues related to a specific industrial activity. Due to their multidimensional nature, the environmental issues cannot be analyzed though a single indicator. For this reason, before the KPIs development, a system of indicators needs to be formalized, aiming at a manageable number of indicators covering all categories [23]. Within the steel sector, the KPI-based assessment of the environmental footprint of the production processes was widely applied in a number of applications covering all the aspects of the environmental impact. In particular, an integrated scenario analysis tool was developed, including process modelling and metrics tools, for process data analyses and scenario simulations [24]. KPIs were developed for monitoring the efficiency of the gas management and the objectives of the optimization were defined [25]. Furthermore, a simulation model aimed at assessing the impact of operation units (i.e. production processes, fumes and wastewater treatment plants) and comparing the environmental and energy impacts related to the production of the most common steel grades [26].

This paper concerns a part of the work developed inside the project entitled "Water and related energy Hub Advanced Management system in steelworks-WHAM", co-funded by the Research Fund for Coal and Steel (RFCS). In the first part, the main technical barriers and factors, that can affect reuse and recirculation of wastewater and energy efficiency, were analysed. Moreover, further barriers, such as environmental and economic issues, were investigated. In addition, the main constraints on water management in the steel industry were taken into account. In the second part the set of KPIs are presented, which were selected in order to monitor the efficiency of water management as well as to be used as objective function for optimization problems.
The paper is organized as follows: Section 2 provides the overall approach of the WHAM project; in Section 3 technical barriers and factors affecting the wastewater reuse and recirculation and the energy efficiency are presented and discussed; Section 4 provides the selection of the KPIs in the WHAM project. Finally, Section 5 proposes some concluding remarks and hints for future work.

\section{The WHAM Project}

The WHAM project aims at minimizing water consumption in steelworks by applying a holistic approach, which combines flexible on-line monitoring, optimization platform and innovative water treatment technologies. The proposed approach includes:

- a system for monitoring, simulating and optimizing the water network, taking into account physical, thermal and chemical qualities of the water. This system will work as decision support system, providing information on the current condition of the water network and analyzing potential upgrades and related benefits;

- proposing new and more effective water purification technologies in terms of both water quality and management costs.

The online monitoring system will provide technical personnel and plant managers with an updated overview of the status of the circuits and of the main qualitative parameters of the water streams. Furthermore, together with the simulation and optimization packages, it will support management of water systems and implementation of suitable corrective actions in order to quickly identify faults and losses of efficiency, correctly handle reuse and recycling and manage water treatments. The optimal water management will be achieved by applying advanced optimization techniques and by providing support to decisions. In particular, according to the main industrial needs and main bottlenecks, specific objective functions will be settled (e.g. by exploiting defined KPIs as they are or through ad-hoc adaptations). Manipulated and controlled variables and constraints will be selected by taking into account plant staff indications and optimization needs. The optimization algorithms will be written in Python language by using ad-hoc packages, which implement robust optimization methods and are free for commercial use. Problem parameters will be provided to the optimization algorithms directly by the on-line monitoring system, which is linked with plant IT, or by exploiting the results of the simulation tool. Therefore, problems belonging to the class of linear, nonlinear and mixed integer programming problems will be addressed. The overall system is expected to facilitate daily work of operators and to lead to consistent savings of freshwater. The use of novel water treatment technologies will help to achieve the final target.

The case studies analysed in WHAM project concern the Rolling area for seamless pipes at TenarisDalmine (located in Dalmine, Bergamo, Italy), the rolling area and 
first rain tanks at Ferriere Nord (located in Osoppo, Udine, Italy) and the finishing line in a Spanish steelworks of ArcelorMittal.

Starting from the analysis of water networks, all factors affecting water recirculation, water treatment efficiency and water network monitoring were identified. Factors, such as water extraction from rivers, wells or other sources, discharge, filtration, cooling, effluent treatment, and water reuse and recycling, were taken into account. Field data were collected, such as physical, chemical, electrochemical and biological parameters of the circulating water (i.e. pH, hardness, temperature, conductivity, suspended solids, oil content, metal concentrations, bacteria content). In particular, the last parameters represent the main fouling agents, affecting the quality of industrial water. This is a crucial aspect of the water management as some water streams can affect the steel products quality, due to the direct contact of water and product within specific steps of the manufacturing chain. On the other hand, the factors that can affect the efficiency of industrial water networks were analysed. In particular, additives (i.e. biocides, anticorrosive and antiscalant agents, detergents, oil-removing agents, and sodium hypochlorite), used in the water circuit aim at improving the plant performances.

In addition, according to the needs of the different facilities, global-purpose Key Performance Indicators were defined.

\section{Technical barriers and relevant factors}

Large amounts of water are used in the different processes of the steel production chain. In particular, water is mainly used for cooling but also for descaling, dust scrubbing and other processes. Consequently, water losses are primarily due to evaporation or as wastewater. All kind of waters are used in the steel sector. First of all, fresh water is used as make-up water and can be provided by different sources, such as rivers and groundwater. However, the main issue is represented by the fresh water availability as well as the water quality. For this reason, water resources management is a key challenge along with climate change for the worldwide community and, consequently, also for the steel sector [1]. In particular, the availability and the quality of fresh water as well as the water regulations represent the main constraints for water management in the steel sector. Starting from these main constraints, the following further factors affecting the water use in the steel sector, considering the main steelmaking processes, were taken into account:

- Older facilities are usually less efficient as, due to their sizes, their retrofitting is often not economically viable;

- Processing techniques are different and they do not show the same efficiency in the water management;

- Different processing steps are required for different water sources showing different characteristics;

- Different products can have different impacts on water consumption.
Furthermore, as water consumption in different facilities presents specific features, continuous improvements for a specific plant should be assessed. Reduction of water consumption can be achieved through efficient use of water, higher recycling rate, water withdrawal reduction, wastewater reduction (e.g. by applying water-saving technologies), water recirculation and outsourcing of available water sources (e.g. rainwater). In this background, process modelling and simulation can forecast process behaviour before plant applications as for instance was described in [27] for the reuse of continuous casting wastewater blowdown in basic oxygen steelmaking gas washing system. In addition, Process Integration contributes to save energy, water and resources [28]. In deeper details and according to [29], within steelworks (as in all kind of process industries) the following three main arrangements are available (see Fig. 1):

- Water reuse (Fig. 1A): blowdown water from one process is (partly) reused in another one, where the contamination from the upstream process can be accepted, and, consequently, water can be used twice or more;

- Water regeneration reuse (Fig. 1B): water reused in a process is reused in another one after a treatment stage, which makes its quality acceptable downstream. The water flows through the user only once;

- Water regeneration recycling (Fig. 1C): water used in the whole system is treated and then recycled. Accordingly, water can be used many times in the whole system.

In order to apply the arrangements presented in Figure 1, the water quality required in each process should be specified. In the steel industry the wastewater reuse/ recycle is commonly applied, in order to reduce the water intake. After cleaning and/or cooling, this results in around $90 \%$ of reused/recycled water [1]. Nevertheless, the volume depends on different boundaries and restrictions, such as plant layout, process constraints, legislation limits and physical conditions. In order to maximise the water reuse/ recycling for all the arrangements, the following common constraints should be taken into account:

- corrosion limitations;

- fouling and scaling limitations;

- foaming limitations;

- minimum of mass transfer driving force;

- minimum flow rate requirements;

- maximum inlet contaminants concentration for upstream process;

- maximum inlet contaminants concentration for downstream treatment;

- product defects due to a bad process water quality.

Furthermore, all the listed arrangements should consider energy efficiency as well. In addition, in the second and third arrangements the exploitation of water treatments, affecting the water reused/recycled and the water management costs, is required.

For instance, direct cooling of hot steel products and some plants components, such as the hot rolling mill cylinders, requires large amount of water and related water 


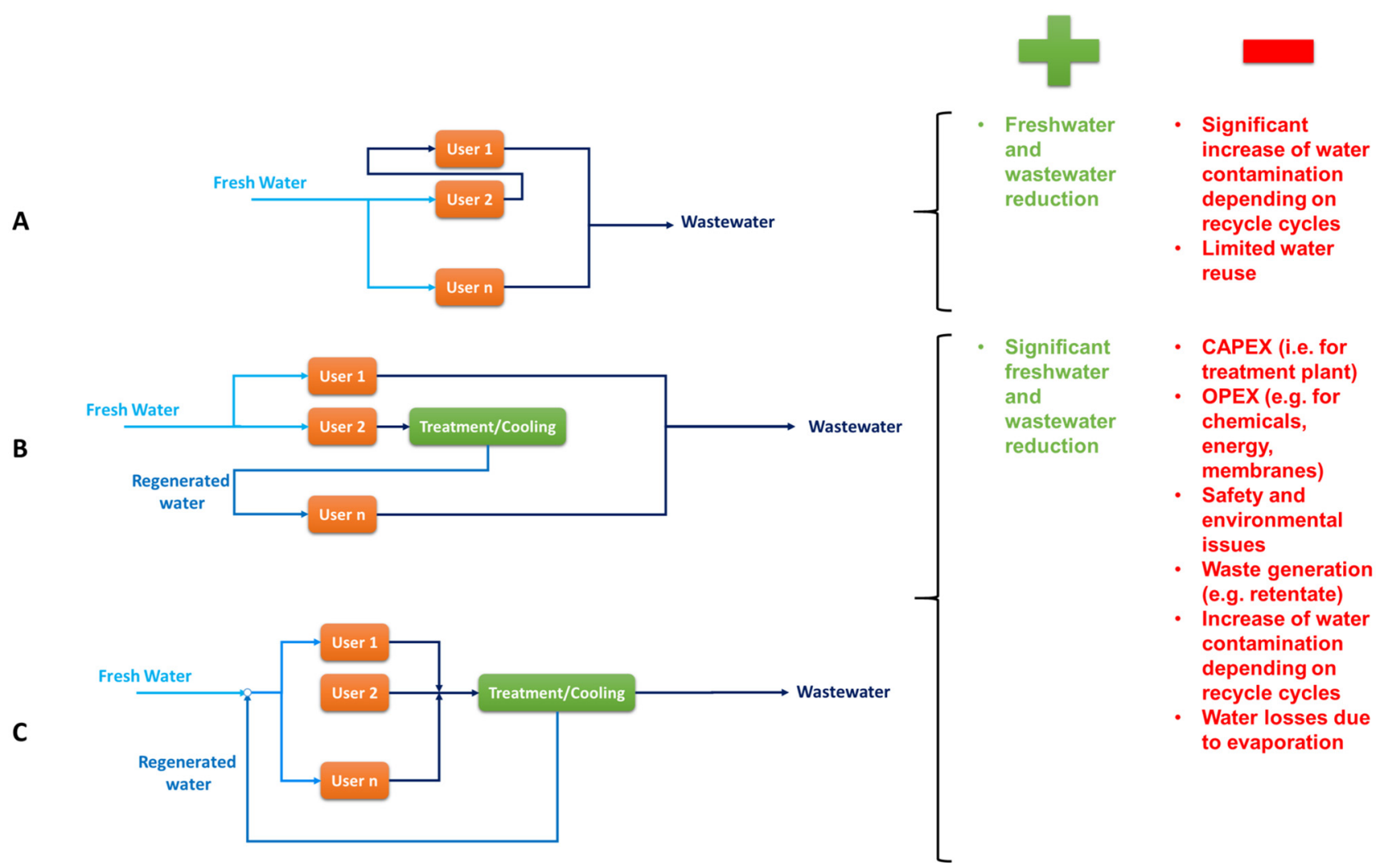

Fig. 1. Water reuse arrangements and related advantages and disadvantages.

circuits often present an open recirculating system with a dedicated water treatment plant.

Concerning the water reuse (Fig. 1A), this procedure makes reducing the freshwater and wastewater volumes possible. However, although strongly recommended, the water reuse is limited, due to the contamination limits of water users. On this subject, some technical barriers for an efficient water management should be taken into account. Concerning the water recirculation, the main specific barrier is represented by the possible increase of contaminant concentrations. This makes reusing water possible only in limited cases, such as in processes accepting certain level of contaminants.

Due to the increase of contaminant concentrations, the water reuse/recycling can be limited, due to the constraints on the amount of contaminants accepted by the water user. In addition, before water reuse/recycling, cooling is often necessary. Accordingly, water used in a process can be treated and/or cooled and afterwards used in a downstream process; otherwise the total amount of used water can be regenerated and subsequently recycled. With these arrangements, that include regeneration (Figs. 1B and 1C), some more significant achievements can be obtained with respect to the "water reuse arrangement", such as for the freshwater and wastewater amount reduction (regeneration and recycling provide the highest reduction). Furthermore, a part of the effluent load is removed before reuse/recycling, by reducing the complexity of the wastewater treatments. However, treatments/cooling processes need to be included in the network. This results in increasing investments and operational costs, which represent further significant barriers. In particular, the main cleaning and cooling treatments need large energy and chemical consumptions as well as the use of consumable parts of equipment (e.g. membranes). Consequently, significant safety and environmental issues can occur. In addition, as above mentioned, recycling increase leads to higher contaminant concentrations, depending on recycling cycles and due to the evaporation increase. This, in turn, produces increased water losses and consequent salts concentrations. For all these reasons, a holistic approach of the whole impact on the water resources makes the evaluation of the water reuse effectiveness possible, taking into account the environmental impacts and potential increase in energy use.

As stated before, in the steel sector water is highly used in cooling operations. Cooling systems can be classified as follows:

- open recirculating cooling water system;

- closed recirculating water system;

- once-through cooling water system.

In the different water cooling circuits, water savings can be obtained, depending of the different configurations. The once-through system uses more water than the recirculating one. On the other hand, in the indirect cooling circuit (i.e. generally the heat exchangers closed circuit where water have no direct contact with the product) more water 
Table 1. Comparison of water intake demands for two water systems for an integrated steel production site of $4 \mathrm{Mt} / \mathrm{y}$ [30].

\begin{tabular}{lccc}
\hline & \multicolumn{2}{c}{ Water intake } & Water savings with recirculation $(\%)$ \\
\cline { 2 - 4 } Water use & Once-through $\left(\mathrm{m}^{3} / \mathrm{min}\right)$ & Extensive recirculation $\left(\mathrm{m}^{3} / \mathrm{min}\right)$ & \\
\hline Indirect cooling & 675 & 7.4 & 98.9 \\
Direct cooling & 265 & 6.2 & 97.7 \\
Process water & 7.7 & 5.1 & 33.8 \\
Potable & 1.5 & 1.5 & 0.0 \\
Global & 949.2 & 20.2 & 97.1 \\
\hline
\end{tabular}

intake is required compared to a direct water circuit (i.e. the direct spraying of water onto products or equipment). The water amounts required for the cooling tower in a oncethrough system and in a recirculation system differ from each other. In indirect and direct cooling systems, the extensive recirculation reduces the total water intake to almost $2.4 \%$ with respect to the demand of the oncethrough system [30]. Table 1 provides an example of water intake demands for main uses in two different types of water systems for an integrated steel production site with a capacity of $4 \mathrm{Mt} / \mathrm{y}$. The first column lists the different water use (they are related to different required water quality), the second and third columns report the figures of water intake requirements related respectively to oncethrough water system and to an extensive recirculation water system and the final column depicts the water savings that can be obtained with recirculation. The reported values in Table 1 well depict the considerations given before. For a better visualization, the numbers reported in Table 1 are compared in Figure 2, which depicts also how the distribution of water intake demands for different uses changes in case of extensive recirculation; in that case, all the main users require comparable water intakes with respect to a more diversified situation in the once-through system.

In order to recycle the water within the same process, suspended solids and oils present in contact cooling waters must be removed. This removal process leads to good performance of the circuit and extends the lifetime of equipment. The water treatment can be performed by settling tanks or decanters, often with the support of coagulants or flocculants, where the suspended solids settle. These treatments work thanks to density differences between solid particles, water and oils; after the phase separations, skimmers or scrapers are used to remove the undesired phases from water. However, these systems are useful for removing big particles and free oils. In order to achieve higher results, filtration units can be used, where sands with variable granularity entraps smaller suspended solids, resulting in a filtered stream with suspended solids characterized by a particle size lower than $100 \mu \mathrm{m}$.

On the other hand, in order to understand how further barriers can face up, advanced treatments should be considered, such as desalination through for instance RO and UF $[17,19,20]$, where the membrane technology shows a promising potential for the treatment of (acidic) process water in the steel industry [31]. Desalination is a fundamental treatment as the increase of salt concentration, due to water evaporation or to direct contamination, can negatively affect process equipment (e.g. hot rolling mills) or product (hot rolled coil). In order to overcome the barrier consisting in the contaminants quantity in the concentrate, UF and the RO implementation can maximize wastewater reuse in different plants. These environmentally friendly (no use of chemicals) treatment technologies produce a high quality recovered permeate, which can be reused, while the concentrate is often suitable to discharging. Although the implementation of UF and RO present economic barriers, due to high investment and operating costs, mainly related to the membranes and energy costs, a significant example of RO application in steelworks, along with other treatments, is the treatment of overflow coming from the clarifiers of the washing water of the Blast Furnace (BF) gas cleaning. They collect water from the BF gas cleaning system, showing high concentrations of ammonia, chloride, calcium and not negligible amount of cyanides; in particular, it is noteworthy that these lasts represent a crucial issue as proved by the recent studies on innovative cyanide treatments. Ozone can provide the optimal means for the minimization or elimination of cyanide releases from the water-supply cycle of BFs, resulting in cyanides completely decomposed, without waste production and the need for other reagents [32]. A process model was developed to test a wide range of operating conditions and wastewater features and to prove the robustness of the process based on ozonation to control cyanide in the wastewater of the BF gas washing system [33]. In addition, after validation, the model was used to analyse scenarios, by considering also real contexts. In particular, pilot tests were extended, process knowledge was improved by obtaining useful suggestions [34]. Therefore, by coupling $\mathrm{RO}$ and ozonation treatments, a considerable amount of $\mathrm{BF}$ gas washing water can be recovered and reused.

After the performed analysis, the main constraints and barriers affecting wastewater reuse and recirculation in steelworks can be summarized as reported in Table 2.

\section{Selected key performance indicators}

In order to assess the sustainability of the water management in an integrated way, a holistic approach was used. On this subject a balanced set of indicators was selected. In particular, the selected KPIs allow measuring pertinent parameters and quantities to simplify complex 


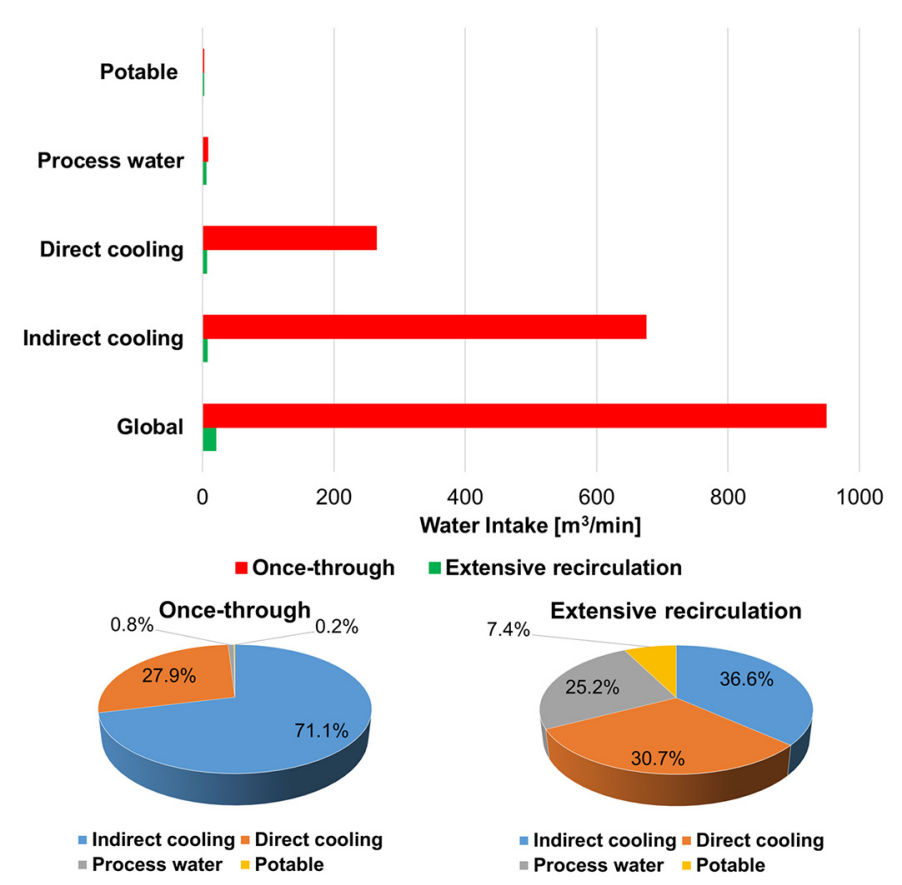

Fig. 2. Comparison between water intakes demands in case of once-through and extensive recirculation water systems (up) and related distribution (down) considering a typical integrated steelmaking plant.

Table 2. Main constraints and barriers for wastewater reuse and recirculation in steelworks.

\begin{tabular}{ll}
\hline Constraints & Barriers \\
\hline Water amount required by the process & Availability of freshwater \\
Water quality impacting process operation & Environmental issues (e.g. related to the use of chemicals) \\
Water quality impacting on & Relevant capital expenditure (e.g. related to the need for \\
health and safety & very efficient treatment processes) \\
Legal requirements & High operating costs (e.g. for pumping and treatments) \\
& Maintenance costs \\
& Reduction of product quality \\
& Reduction of discharging water quality \\
\hline
\end{tabular}

variables, providing easy information on water management. Through this approach different efficiency and effectiveness aspects can be measured and quantified, by providing a comprehensive perspective concerning all impacts on water resources.

Concerning the WHAM project, 22 KPIs were selected starting from literature and operational practices, as presented in Table 3. They aim at monitoring and assessing the environmental performance of the water management in steelmaking processes as well as at monitoring the efficiency of new treatments of wastewater [35]. Furthermore, the economic viability and the economic impact of water management were taken into account, by selecting a list of 8 Economic Key Performance Indicators (EKPIs), listed in Table 4. These indicators take into account costs of the total water used as well as the operating costs. They will allow evaluating not only the water treatment technologies, but also estimating the effectiveness of water saving. They, were subdivided in five categories that allow analysing all economic aspects of water management, such as energy costs, staff costs, reagents costs, waste costs, costs of maintenance.

Going to more detail, the indicators selected in this work will aim at reflecting the status as well as the progress of water management. This will be carried out by monitoring the efficiency through some simplified analyses that usually would be difficult and subjective to be performed. If significant improvements are achieved in water management, KPIs 1, 2, 3, 4, 6, 7, 17 are expected to decrease. This involves also the energy KPIs, such as KPIs $18,19,20,21,22$. This is also reflected in the increase of KPIs 5, 8, 9, 10 and, in absolute terms, of KPIs related to the treatments' efficiency, that are KPIs 11 (Change in total suspended solids), 12 (Change in chemical oxygen demand), 13 (Change in biochemical oxygen demand), 14 (Change in bacteria load), 15 (Change in electrical conductivity), 16 (Change in Hardness). Consequently, a good compromise between the improvement of both 
Table 3. Key Performance Indicators for water management.

\begin{tabular}{llllll}
\hline N. KPI Name & Description & U.M. & Scope-Facilities & $\begin{array}{l}\text { Calculation/ } \\
\text { Evaluation method }\end{array}$ \\
\hline 1 & $\begin{array}{l}\text { Total freshwater } \\
\text { withdrawal }\end{array}$ & $\begin{array}{l}\text { Water quantity } \\
\text { extracted from } \\
\text { steelworks sources } \\
\text { (e.g. wells or rivers) }\end{array}$ & $\mathrm{m}^{3}$ & - & Measured \\
& A & & & \\
& & &
\end{tabular}

2 Specific water consumption

3 Percentage of blowdown water

4 Specific freshwater consumption

5 Specific recycled water

6 Specific sewage emission

$7 \quad$ Specific water losses

Amount of water losses per ton steel

8 Water resource efficiency $(\gamma)$

9 Water circulation rate $(\mu)$

10 Water environmental efficiency $(\eta)$

11 Change in total suspended solids (TSS)

12 Change in chemical oxygen demand (COD) produced.

discharged into the withdrawal for industrial use production

Amount of water

Amount of sewage

fresh water process water to the total water consumption TSS $(\mathrm{mg} / \mathrm{L})$ in discharged/treated COD $(\mathrm{mg} / \mathrm{L})$ in discharged/treated
Amount of water used when a ton of steel is

Ratio between water \% water body and water

Direct specific use of fresh water for steel recycled per ton steel. emission per ton steel.

$\mathrm{m}^{3} / \mathrm{t}_{\mathrm{ss}}\left(\mathrm{m}^{3} / \mathrm{t}_{\mathrm{LS}}\right)$ efficiency

$\mathrm{m}^{3} / \mathrm{t}_{\mathrm{ss}}\left(\mathrm{m}^{3} / \mathrm{t}_{\mathrm{LS}}\right)$ It reflects water-

$\mathrm{m}^{3} / \mathrm{t}_{\mathrm{sS}}\left(\mathrm{m}^{3} / \mathrm{t}_{\mathrm{LS}}\right)$ It assesses water

$\mathrm{m}^{3} / \mathrm{t}_{\mathrm{sS}}\left(\mathrm{m}^{3} / \mathrm{t}_{\mathrm{LS}}\right)$ It is useful for closing

Comparison between - $\quad$ It indirectly assesses consumption and total water consumption in a specific production

Ratio of recycled $\%$

Reciprocal of sewage emission per ton steel.

Difference between $\quad \mathrm{mg} / \mathrm{L}$ water and TSS (mg/

L) in incoming water Difference between $\quad \mathrm{mg} / \mathrm{L}$ water and COD (mg/ L) in incoming water of TSS It assesses water use technology and measure water saving effectiveness

It measures the percentage of discharged water with respect to the total water withdrawal recycle technology. saving effectiveness and the environmental impacts. the water balance and in order to evaluate possibilities of losses recovery the use of industrial fresh water and water use technologies

Total water use $\left(\mathrm{m}^{3}\right) /$ Produced steel $\left(t_{\mathrm{ss}}\right.$ or $\left.t_{L S}\right)$

(Discharged Water $\left(\mathrm{m}^{3}\right) /$ Total water withdrawal $\left.\left(\mathrm{m}^{3}\right)\right)^{*} 100$

Total freshwater withdrawal/Produced Steel ( $t_{\mathrm{ss}}$ or $t_{\mathrm{LS}}$ ) Recycled Water/ Produced Steel $\left(\mathrm{t}_{\mathrm{ss}}\right.$ or $\left.t_{L S}\right)$

Discharged Water $\left(\mathrm{m}^{3}\right) /$ Produced Steel $\left(t_{\mathrm{ss}}\right.$ or $\left.\mathrm{t}_{\mathrm{LS}}\right)$

(Total freshwater withdrawal Discharged Water $\left(\mathrm{m}^{3}\right)$ )/Produced Steel $\left(t_{\mathrm{ss}}\right.$ or $\left.\mathrm{t}_{\mathrm{LS}}\right)$ $\gamma=1 /$ Fresh water consumption/Total water consumption)

It assesses water resource use and water use technology

$t_{\mathrm{sS}} / \mathrm{m}^{3}\left(\mathrm{t}_{\mathrm{LS}} / \mathrm{m}^{3}\right)$ It assesses the environment friendly degree during water consumption.

It assesses treatments efficiency in removal efficiency in removal of COD
TSS in discharged/ treated water - TSS in incoming water

COD in discharged/ treated water - COD

in incoming water

$\mu=$ Recycled water consumption/Water consumption x $100 \%$ $\eta=1 /$ Specific Sewage emission 
Table 3. (continued).

\begin{tabular}{|c|c|c|c|c|c|}
\hline N. & KPI Name & Description & U.M. & Scope-Facilities & $\begin{array}{l}\text { Calculation/ } \\
\text { Evaluation method }\end{array}$ \\
\hline 13 & $\begin{array}{l}\text { Change in biochemical } \\
\text { oxygen demand } \\
\text { (BOD) }\end{array}$ & $\begin{array}{l}\text { Difference between } \\
\text { BOD }(\mathrm{mg} / \mathrm{L}) \text { in } \\
\text { discharged/treated } \\
\text { water and BOD }(\mathrm{mg} / \\
\mathrm{L}) \text { in incoming water }\end{array}$ & $\mathrm{mg} / \mathrm{L}$ & $\begin{array}{l}\text { It assesses treatments } \\
\text { efficiency in removal } \\
\text { of BOD }\end{array}$ & $\begin{array}{l}\text { BOD in discharged/ } \\
\text { treated water - BOD } \\
\text { in incoming water }\end{array}$ \\
\hline 14 & $\begin{array}{l}\text { Change in bacteria } \\
\text { load (BL) }\end{array}$ & $\begin{array}{l}\text { Difference between BL } \\
(\mathrm{CFU} / \mathrm{mL}) \text { in } \\
\text { discharged/treated } \\
\text { water and } \mathrm{BL}(\mathrm{CFU} / \\
\mathrm{mL}) \text { in incoming } \\
\text { water }\end{array}$ & $\mathrm{CFU} / \mathrm{mL}$ & $\begin{array}{l}\text { It assesses treatments } \\
\text { efficiency in removal } \\
\text { of bacteria }\end{array}$ & $\begin{array}{l}\text { BL in discharged/ } \\
\text { treated water - BL in } \\
\text { incoming water }\end{array}$ \\
\hline 15 & $\begin{array}{l}\text { Change in electrical } \\
\text { conductivity (EC) }\end{array}$ & $\begin{array}{l}\text { Difference between EC } \\
(\mu \mathrm{S} / \mathrm{cm}) \text { in } \\
\text { discharged/treated } \\
\text { water and EC }(\mu \mathrm{S} / \\
\mathrm{cm}) \text { in incoming water }\end{array}$ & $\mu \mathrm{S} / \mathrm{cm}$ & $\begin{array}{l}\text { It assesses efficiency of } \\
\text { treatments/water } \\
\text { management in EC } \\
\text { control }\end{array}$ & $\begin{array}{l}\text { EC in discharged/ } \\
\text { treated water - EC in } \\
\text { incoming water }\end{array}$ \\
\hline 16 & $\begin{array}{l}\text { Change in Hardness } \\
\text { (Ha) }\end{array}$ & $\begin{array}{l}\text { Difference between Ha } \\
\left({ }^{\circ} \mathrm{fH}\right) \text { in discharged/ } \\
\text { treated water and } \mathrm{Ha} \\
\left({ }^{\circ} \mathrm{fH}\right) \text { in incoming } \\
\text { water }\end{array}$ & ${ }^{\circ} \mathrm{fH}$ & $\begin{array}{l}\text { It assesses efficiency of } \\
\text { treatments/water } \\
\text { management in the } \\
\text { Ha control }\end{array}$ & $\begin{array}{l}\text { Ha in discharged/ } \\
\text { treated water - Ha in } \\
\text { incoming water }\end{array}$ \\
\hline 17 & Specific additives used & $\begin{array}{l}\text { Additives with } \\
\text { different purposes } \\
\text { (biocides, } \\
\text { anticorrosive, anti- } \\
\text { scaling agents, } \\
\text { detergents) that are } \\
\text { added into the circuits }\end{array}$ & $\mathrm{g} / \mathrm{L}\left(\mathrm{L} / \mathrm{m}^{3}\right)$ & $\begin{array}{l}\text { It quantifies the total } \\
\text { amount of used } \\
\text { additives }\end{array}$ & $\begin{array}{l}\text { Sum of all the } \\
\text { exploited additives (g } \\
\text { or } \mathrm{L}) / \text { Total water use } \\
\left(\mathrm{m}^{3}\right)\end{array}$ \\
\hline 18 & $\begin{array}{l}\text { Energy consumption } \\
\text { for water treatment }\end{array}$ & $\begin{array}{l}\text { Amount of energy } \\
\text { consumed during the } \\
\text { treatment of process } \\
\text { water }\end{array}$ & $\mathrm{kJ}$ & - & $\begin{array}{l}\text { Sum of the energy } \\
\text { consumed during the } \\
\text { treatment of process } \\
\text { water }\end{array}$ \\
\hline 19 & $\begin{array}{l}\text { Energy consumption } \\
\text { for water pumping }\end{array}$ & $\begin{array}{l}\text { Amount of energy } \\
\text { consumed by the } \\
\text { pumps }\end{array}$ & $\mathrm{kJ}$ & - & $\begin{array}{l}\text { Sum of the energy } \\
\text { used by the pumps }\end{array}$ \\
\hline 20 & $\begin{array}{l}\text { Other energy } \\
\text { consumption related } \\
\text { to water management }\end{array}$ & $\begin{array}{l}\text { Amount of energy } \\
\text { consumed during } \\
\text { management of water } \\
\text { that is not included in } \\
\text { KPIs } 16 \text { and } 17\end{array}$ & $\mathrm{~kJ}$ & - & $\begin{array}{l}\text { Sum of the energy in } \\
\text { water management } \\
\text { (no treatment, no } \\
\text { pumps) }\end{array}$ \\
\hline 21 & $\begin{array}{l}\text { Total energy } \\
\text { consumption }\end{array}$ & $\begin{array}{l}\text { Total energy } \\
\text { consumption for water } \\
\text { management }\end{array}$ & $\mathrm{kJ}$ & - & $\begin{array}{l}\text { KPI } 16+\text { KPI } \\
17+\text { KPI } 18\end{array}$ \\
\hline 22 & $\begin{array}{l}\text { Specific energy } \\
\text { consumption }\end{array}$ & $\begin{array}{l}\text { Specific energy } \\
\text { consumption }\end{array}$ & $\mathrm{kJ} / \mathrm{t}_{\mathrm{ss}}\left(\mathrm{kJ} / \mathrm{t}_{\mathrm{LS}}\right)$ & $\begin{array}{l}\text { It measures the } \\
\text { specific energy } \\
\text { consumption related } \\
\text { to water management }\end{array}$ & $\begin{array}{l}\text { KPI } 19(\mathrm{~kJ}) / \text { Produced } \\
\text { Steel }\left(\mathrm{t}_{\mathrm{ss}} \text { or } \mathrm{t}_{\mathrm{LS}}\right)\end{array}$ \\
\hline
\end{tabular}

KPIs and EKPIs is expected and, for this reason, a right choice of objective functions is necessary in provided optimization studies. These objective functions can be some KPIs in their current form or after modifications or combinations. The information provided by KPIs can allow detecting significant trends and impacts. Therefore, if the previous listed expectations are not achieved and undesirable results are reached, the corresponding values of KPIs will allow the rapid identification of suitable countermeasures. 
Table 4. Economic Key Performance Indicators for water management.

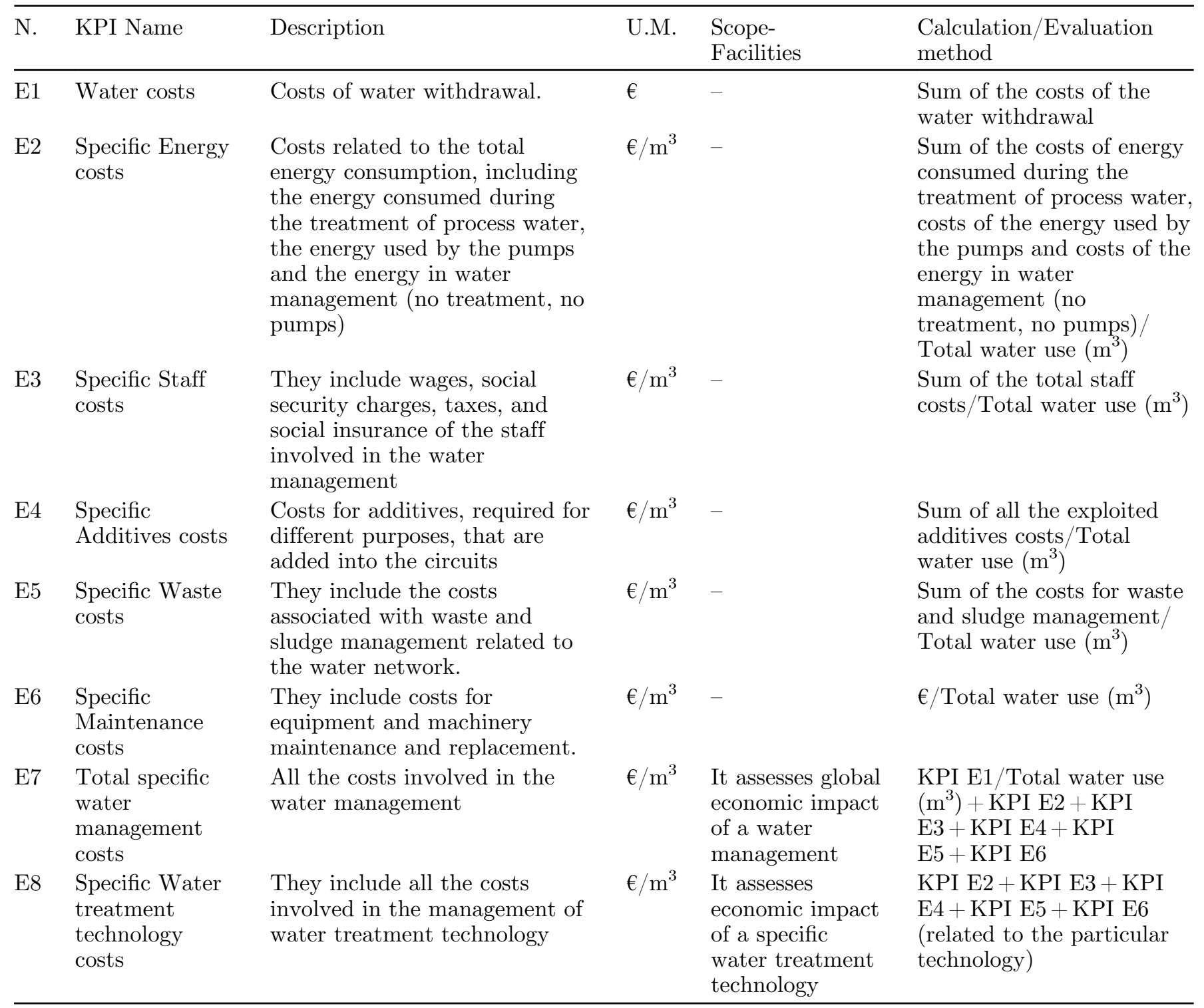

\section{Conclusions}

Within the paper, the factors affecting the lack of efficiency of the industrial water networks and of water treatments were analyzed. Moreover, the main technical barriers and factors affecting the reuse and the recirculation of wastewater as well as energy and monitoring systems efficiencies were considered. A list of KPIs was also proposed, which were selected within an ongoing EUfunded research project, aiming at optimizing the water networks management in steelworks by minimizing the freshwater consumption. Such KPIs will help monitor the environmental and economic performances of water management and the efficiency and economic viability of new water treatments in the steelworks. Furthermore, some KPIs will be used as objective functions, as they are or after ad-hoc adaptations, for the optimization problems that are under development.

In the future work, the KPI-based analysis will exploit not only real data provided by the industrial partners but also the results coming from the simulation work. In particular, water networks simulation, coupled to on-line monitoring system, will provide a picture of the status of the circuits on the main quantitative and qualitative parameters of the water streams, in case of both usual and new scenarios, by supporting correct management of the water systems and suitable corrective actions to identify faults and losses of efficiency. A quantification of the system performances will be available to the user through the defined KPIs, by facilitating critical assessment of the results and adoption of the most suitable solutions. This 
approach is expected to support further implementation of reuse and recycling options as well as management water treatments in order to save freshwater. Therefore, suitable simulation tools are being developed within the project by means of the Modelica language, which will allow the construction of flowsheet-based models and the development of scenario analyses aimed at assessing the viability of some significant changes of processes and operating practices. Furthermore, KPIs, computed through the exploitation of laboratory or pilot test results on new water treatment techniques, will be revised by some multiplicative scale factors, in accordance to suggestions provided by technology developers. This will allow a realistic assessment of the viability of the application of the new technologies at full scale, by considering potential advantages and drawbacks.

Acknowledgements. The work described in this paper was developed within the project entitled "WHAM-Water and related energy Hub Advanced Management system in steelworks" (Grant Agreement number: 800654-WHAM), which has received funding from the Research Fund for Coal and Steel of the European Union. The sole responsibility of the issues treated in this paper lies with the authors; the Commission is not responsible for any use that may be made of the information contained therein.

\section{References}

1. World Steel Association, Water management in the steel industry, position paper, World Steel Association 2015, ISBN 978-2-930069-81-4

2. Y. Gu, J. Xu, A.A. Keller, et al., Calculation of water footprint of the iron and steel industry: a case study in Eastern China, J. Clean. Prod. 92, 274-281 (2015)

3. S.R. Kalvani, A.H. Sharaai, L.A. Manaf, A.H. Hamidian, Review On Water Footprint Method In Different Sectors, Int. J. Adv. Sci. Technol. 29, 1778-1785 (2020)

4. G.F. Porzio, E. Alcamisi, I. Matino, V. Colla, An integrated approach for industrial water systems optimal design, in: Technical Proceedings of the 2014 NSTI Nanotechnology Conference and Expo, NSTI-Nanotech 2014, Vol.3, 2014, pp. 529-532

5. S. Roudier, L.D. Sancho, R. Remus, M. Aguadomonsonet, Best Available Techniques (BAT) reference document for iron and steel production. Industrial Emissions Directive 2010/75/EU: Integrated Pollution Prevention and Control, Institute for Prospective and Technological Studies, Joint Research Centre, European Commission, 2013

6. T.A. Branca, B. Fornai, V. Colla, M.M. Murri, E. Streppa, A. J. Schröder, The challenge of digitalization in the steel sector, Metals 10, 2 (2020)

7. J. Wang, S. Li, G. Xiong, D. Cang, Application of digital technologies about water network in steel industry, Resour. Conserv. Recycl. 55(8), 755-759 (2011)

8. C. Deng, W. Jiang, W. Zhou, X. Feng, New superstructurebased optimization of property-based industrial water system, J. Clean. Prod. 189, 878-886 (2018)

9. I. Matino, E. Alcamisi, G.F. Porzio, V. Colla, Application of Unconventional Techniques for Evaluation and Monitoring of Physico-Chemical Properties of Water Streams, Int. J. Simul. Syst. Sci. Technol. 16, 1 (2015)
10. E. Alcamisi, I. Matino, M. Vannocci, V. Colla, Simplified Ionic Representation of Industrial Water Streams, in: 8th European Modeling Symposium on Mathematical Modeling and Computer simulation EMS2014, Pisa, Italy, pp. 286-290, (2014)

11. I.A. Katsoyuannis, P. Gkotsis, M. Castellana, F. Cartechini, A.I. Zouboulis, Production of demineralized water for use in thermal power stations by advanced treatment of secondary wastewater effluent, J. Environ. Manag. 190, 132-139 (2017)

12. B. Das, B. Chakrabarty, P. Barkakati, Preparation and Characterization of novel Ceramic Membranes for MicroFiltration Applications, Ceram. Int. 43, 13 (2016)

13. W. Liu, N. Canfield, Development of thin porous metal sheet as micro-filtration membrane and inorganic membrane support, J. Membr. Sci. 409(10), 113-126 (2012)

14. C. Dong, G. He, H. Li, Y. Han, Y. Deng, Antifouling enhancement of poly(vinylidene fluoride) microfiltration membrane by adding $\mathrm{Mg}(\mathrm{OH})_{2}$ nanoparticles, J. Membr. Sci. 387-388, 40-47 (2012)

15. J. Liu, J. Tian, Z. Wang, D. Zhao, F. Jia, B. Dong, Mechanism analysis of powdered activated carbon controlling microfiltration membrane fouling in surface water treatment, Coll. Surf. A: Phydicochem. Eng. Aspects 517, 45-51 (2017)

16. J. Liu, B. Dong, B. Cao, D. Zhao, Z. Wang, Microfiltration process for surface water treatment: irreversible fouling identification and chemical cleaning, RSC Adv. 6, 115 (2016)

17. V. Colla, I. Matino, T.A. Branca, B. Fornai, L. Romaniello, F. Rosito, Efficient Use of Water Resources in the Steel Industry, Water 9(11), 874 (2017)

18. I. Matino, V. Colla, L. Romaniello, F. Rosito, L. Portulano, Simulation techniques for an efficient use of resources: An overview for the steelmaking field, in: World Congress on Sustainable Technologies (WCST), IEEE, 2015, pp. $48-54$

19. I. Matino, B. Fornai, V. Colla, L. Romaniello, F. Rosito, Water Process Integration: Assessment of an Ultrafiltration and Reverse Osmosis Based Treatment to Regenerate Coke-Making Area Wastewater, in: Proceedings of European Steel Technology and Application Days (ESTAD 2017)

20. V. Colla, T.A. Branca, F. Rosito, C. Lucca, B.P. Vivas, V.M. Delmiro, Sustainable reverse osmosis application for wastewater treatment in the steel industry, J. Clean. Prod. 130, 103-115 (2016)

21. I. Matino, V. Colla, F. Cirilli, et al., Environmental impact evaluation for effective resource management in EAF steelmaking, Metall. Ital. 10, 48-58 (2017)

22. Eurofer, Susteel - Sustainability for steel construction products mark - Definition of the KPI system, (2012)

23. J.M. Fernández, F.R. Pérez, M.G. Huerta, A.S. Vizán, Methodology for the selection of key performance indicators for sustainable steel production through an intelligent control system use, Project Manag. Eng. Res. 89-102 (2014)

24. V. Colla, I. Matino, F. Cirilli, et al., Improving energy and resource efficiency of electric steelmaking through simulation tools and process data analyses, Materiaux \& Techniques 104, 6-7 (2016)

25. V. Colla, I. Matino, S. Dettori, et al., Assessing the efficiency of the off-gas network management in integrated steelworks, Materiaux \& Techniques 107, 1 (2019)

26. I. Matino, V. Colla, V. Colucci, P. Lamia, S. Baragiola, C. Di Cecca, Improving sustainability of electric steelworks through process simulations, Chem. Eng. Trans. 52, 763-768 (2016) 
27. E. Alcamisi, I. Matino, V. Colla, A. Maddaloni, L. Romaniello, F. Rosito, Process Integration Solutions for Water Networks in Integrated Steel Making Plants, Chem. Eng. Trans. 45, 37-42 (2015)

28. J.J. Klemeš, P.S. Varbanov, S.R.W. Alwi, Z.A. Manan, Sustainable Process Integration and Intensification: Saving Energy, Water and Resources, Walter de Gruyter GmbH \& Co KG, 2018

29. R.M. Smith, Chemical Process: Design and Integration, John Wiley \& Sons, Ltd., Chichester, West Sussex, United Kingdom, 2005

30. UNEP's Finance Industry Initiatives, Industry as a Partner for Sustainable Development. Finance and Insurance, Geneva, Switzerland, 2002

31. R. Wolters, M. Hubrich, M. Kozariszczuk, P. Mund, J. Kamp, M. Wessling, Treatment of Cooling and Process Water in the Steel Industry, Chem.-Ingenieur-Tech. 91(10), 1445-1453 (2019)

32. Y.P. Luzin, V. Kazyuta, N. Mozharenko, A. Zen'kovich, Removal of cyanides from blast-furnace gas and wastewater, Steel Transl. 42(7), 606-610 (2012)

33. I. Matino, V. Colla, Modelling of an Ozonation Process for Cyanide Removal from Blast Furnace Gas-Washing Water and Analyses of Process Behaviour in Different Scenarios, Chem. Eng. Trans. 61, 1447-1452 (2017)

34. I. Matino, V. Colla, T.A. Branca, Extension of pilot tests of cyanide elimination by ozone from blast furnace gas washing water through Aspen Plus ${ }^{\circledR}$ based model, Front. Chem. Sci. Eng. 12, 718-730 (2018)

35. V. Colla, F. Cirilli, B. Kleimt, et al., Monitoring the environmental and energy impacts of electric arc furnace steelmaking, Matériaux \& Techniques 104, 102 (2016)

Cite this article as: Teresa Annunziata Branca, Ismael Matino, Valentina Colla, Alice Petrucciani, Amarjit Kuor Maria Singh, Antonella Zaccara, Teresa Beone, Luca De Cecco, Ville Hakala, Davide Lorito, Santiago Moreira, Elisa Piras, Paving the way for the optimization of water consumption in the steelmaking processes: barriers, analysis and KPIs definition, Matériaux \& Techniques 108, $510(2020)$ 